\title{
Lomber Faset Sendromu
}

\section{Lumbar Facet Syndrome}

Fatih Baygutalp, Kazım Şenel*

Bölge Eğitim ve Araştırma Hastanesi, Fizik Tedavi ve Rehabilitasyon Kliniği, Erzurum, Türkiye *Atatürk Üniversitesi Tıp Fakültesi, Fiziksel Tıp ve Rehabilitasyon Anabilim Dalı, Erzurum, Türkiye

\section{Özet}

Bel ağrısı Özürlülüğe ve işgücü kaybına yol açabilen, tanı ve tedavi maliyeti yüksek bir hastalıktır. Bel ağrısının yaşam boyu prevelansı \%84 olarak bildirilmektedir. Lomber omurgada en yaygın ağrı sebebi disk olarak kabul edilse de, incelenen popülasyona bağlı olarak faset sendromunun kronik bel ağrısının \%15-40'ından sorumlu olduğu tahmin edilmektedir. Lomber faset sendromu (LFS) prevelansı \%5-90 arasında değişmektedir. Fakat, bu sendromun klinik önemine ve araştırmaların çokluğuna rağmen, tanıdan tedaviye kadar tartışmalar halen devam etmektedir. Bu derlemede lomber faset eklemlerin anatomisi, biyomekaniği ile LFS'nin etyopatogenezi, kliniği, tanı ve tedavisi gözden geçirilmiştir. (Türk Osteoporoz Dergisi 2013;19: 90-4)

Anahtar kelimeler: Bel ağrısı, lomber bölge, Faset sendromu

\section{Summary}

Low back pain is a disease that may lead to disability and work loss, and the cost ofit has high diagnosis and treatment is highcost. Lifetime prevalence of the low back pain is reported to be $84 \%$. Although disc is considered to be the most common pain cause of lumbar spine; depending on the population studied, facet syndrome is estimated to be responsible for $15-40 \%$ of chronic low back pain. Lumbar facet sydrome (LFS) is one of the significant causes of chronic low back pain and its prevalence ranges between $5 \%$ and $90 \%$. Despite the clinical significance of the disease and a high number of studies available, debates on diagnosis and treatment are still ongoing. In this article the anatomical structures and biomechanics of the lumbar facet joints, as well as the etiopathogenesis, clinical presentation, diagnosis, diagnosis and treatment of LFS were reviewed. (Turkish Journal of Osteoporosis 2013;19: 90-4)

Key words: Low back pain, lumbar spine, Facet syndrome

\section{Giriș}

Lomber faset sendromu (LFS) lomber bölgedeki faset (apofizer veya zigapofizeal) eklemlerinin dejeneratif ve travmatik nedenlere bağı olarak ortaya çıkan mekanik instabilite sendromudur. Zigapofizeal terimi Yunanca fazlalık, büyüme anlamındaki "physis" ile bağ veya köprü anlamındaki "zygos" kelimelerinden türetilmiştir.

Goldwaith ilk olarak 1911 ylında faset eklemlerinin ağrı oluşturabileceğinden bahsetmiştir (1). Victor Putti, 1927 yılında yayınlanan bir kadavra çalışmasında bel ve siyatik ağrılarının oluşumunun, zigapofizeal eklemlerin dejeneratif değişikliğine bağlı olabileceğini ve bu dejenerasyonunda 40 yaşından sonra daha sık görüldüğünü belirtmiştir (2). "Faset sendromu" terimi ilk kez 1933 yılında faset hipertrofisinin sinir kök sıkışması ve bel ağrısına yol açabileceğini öne süren Ghormley tarafından kullanılmıştır (3). 1960-1970'lerde ise araştırmacılar normal faset eklemlerine provokatif serum fizyolojik enjeksiyonu ile alt bel ağrısının oluşturulduğunu gösterdiler, bu da faset eklemlerinin ağrı oluşturabileceği kavramını güçlendirmiştir (4,5). Rees, 1971 ylında zigoapofizer eklemi innerve eden Lushka'nın aberran siniri olarak da tarif edilen posterior artiküler sinirin seksiyonu ile inatçı bel ve siyatik ağrılarının tedavi edilebileceğini belirtmiştir $(6,7)$.

Bel ağrısı, erişkinlerde en sık rastlanan kas-iskelet sistemi sorunlarından biridir. Lomber omurgada en yaygın ağı sebebi disk olarak kabul edilse de, incelenen popülasyona bağlı olarak faset sendromunun kronik bel ağrısının \%15-40'ından sorumlu olduğu tahmin edilmiştir $(8,9)$. Faset sendromu prevelansını araştıran çalışmalarda bu oran \%5-90 arasında değişir. 


\section{Anatomi}

Omurgayı oluşturan yapılar ön segmentte vertebra korpusları ile diskler, arka segmentte ise nöral ark bulunur. Lomber bölgenin ağriya duyarlı yapıları; ön segmentte vertebra cismi periostu, anulus fibrosusun posterior bölümü, kaslar, posterior longitudunal ligaman, anterior longitudunal ligaman. Arka segmentte ise nöral ark, ligamanlar, faset eklemleri, sinir kökü, duramater, kaslar ve damarlardır $(10,11)$. Nöral ark, arkus vertebra ile sağ ve sol olmak üzere iki adet faset ekleminden oluşur. Faset eklemleri alttaki vertebranın prosesus zygoapophysealis superiorları ile üstteki vertebranın prosesus zygoapophysealis inferiorları arasında oluşan plana tipinde, kapsüllü, diartrodial ve sinovyal eklemlerdir. Her faset ekleminde dar bir eklem arası açıklğı vardır ve çok sınırlı kayma hareketi yapar. Faset ekleminde 1-2 ml arasında sIvı, sinoviyal membran, 2-4 mm kalınlı̆ında hiyalin kartilaj ve yaklaşık 1 mm kalınlığında fibröz kapsül bulunur. Faset eklem kapsülü iki tabakadan oluşur, yoğun şekilde paralel kollajen liflerden oluşan bir dış tabaka ile düzensiz yerleşimli elastik liflerden oluşan bir iç tabakadan meydana gelir $(12,13)$. Faset eklemleri eklem boşluğuna uzanan eklem kapsülünün rudimenter invajinasyonlar olan menisküslere sahiptir. Menisküsün fonksiyonu, yükleri daha büyük eklem yüzeyleri boyunca dağıtmak ve stabiliteye katkıda bulunmaktır (9).

Eklem kapsülü, sinoviyal membranı ve periostunda serbest sinir uçları bulunduğu için ağrıya hassas yapılardır. Histolojik çalışmalarda lomber faset eklem kapsüllerinin serbest sinir uçlarılya zengin bir şekilde innerve edildiği gösterilmiştir. Kapsülde substans $P$, kalsitonin ve nöropeptid $Y$ içeren sinir sonlanımları bulunmuştur $(14,15)$. Ayrıca dejeneratif lomber vertebra hastalıklarında, faset eklem kartilajı ve sinoviyal dokuda prostaglandinler gibi enflamatuvar mediyatörler (16) ile interlökin 1-beta, interlökin-6 ve tümör nekroz faktör alfa (TNF- $\alpha$ ) bulunmuştur (17).

Faset eklemlerinin innervasyonunu posterior primer ramusun medial dalının lifleri ve sinovertebral sinirin (meningeal veya rekürren sinir) dorsal dalı sağlamaktadır. Dorsal primer ramus 3 dalyla beraber (medial, intermediate ve lateral) vertebral korpusunun arka yarııını, paraspinal kasları, faset eklemleri innerve eder ve belin duyusunu sağlar. Medial dal en önemli daldır, faset eklemini ve lomber multifidi kasını innerve etmesinden dolayı, faset eklem kaynakı ağrının tedavisinde kullanılan radyofrekans nörotomi için hedeftir (18). Medial dallar daha sonra çıkan ve inen eklem dalları olmak üzere komşu faset eklemlerine iki dal verir. Örneğin, L2-L3 faseti L1 ve L2 medial dallarınca innerve edilir. Faset eklem kaynaklı ağrının geniş bir alana yayılmasında bu zengin innervasyonun rol oynadığı düşünülmektedir Bazı insanlar faset eklemlerinde aberran veya ilave inervasyona sahip olabilirler. Faset eklemlerinin innervasyonu, medial dal blokajı ve radyofrekans nörotomisi gibi tanısal ve terapötik faset eklem işlemlerini gerçekleştiren klinisyenler için çok önemlidir. Faset eklemlerinin ya da posterior primer ramus medial dallarının lokal anestezi ile blokajinın bel ağrıı hastalarda ağrıyı hafiflettiği gösterilmiştir $(19,20)$.

\section{Lomber Faset Eklem Biyomekaniği}

Omurganın hareketi kaslar ve sinirlerin koordine çalışması ile gerçekleşmektedir. Hareket açıklığı omurganın her seviyesinde fasetlerin oryantasyonuna göre ve yaş ile değişmektedir. Yaşlanma ile birlikte \%50'ye kadar kayıp oluşabilmektedir. Hareket açıklığı longitudinal ligamanların uzama yeteneği, faset eklem kapsüllerinin elastisitesi, diskin sıv içeriği ve kasların elastisitesi tarafından belirlenir. Faset eklemlerinin dizilimleri veya eklemin aksı vertebranın hareket yönünü belirler. Faset eklemlerinin konumu seviyeye göre değişkenlik gösterir. Lomber bölgede sagittal plana göre yatay düzlemle $80-90^{\circ}$ lik açı yapmaktadır. Buna bağlı olarak lomber bölgede fleksiyon ve ekstansiyon hareket açıklğııın fazla olmasına karşın lateral hareket ve rotasyonlar oldukça kısitlidır $(2,21)$. Faset eklemleri ile birlikte destekleyici ligamanlar da harekete katılarak vertebral kolonun aşırı hareketini kssıtlarlar. Diskin hacim ve yükseklik değişiklikleri daima faset eklemlerde de değişikliklere neden olmaktadır (22).

Lomber faset eklemlerinin asıl görevi torsiyone güçlere karşı durarak fleksiyon ve ekstansiyon hareketi sırasında stabilizasyonu sağlamak, vertebra gövdelerinin kaymasına veya burkulmasına engel olarak bir kilit mekanizması oluşturmaktır. Faset eklemleri fleksiyon hareketinde fazla rotasyona dayanamazlar. Fleksiyon postüründe yapılan rotasyonel hareketler, lomber omurgadaki torsiyonel makaslama kurvetini artırmak suretiyle diskler için büyük risk oluştururlar. Alt lomber faset eklemleri aksiyal düzlemde sıklikla "c" şeklindedir. Dejeneratif spondilolistezis ile daha sagittal yerleşen alt lomber fasetler arasında pozitif bir ilişki saptanmıştır $(23,24)$.

Omurganın pozisyonuna göre diskin ve fasetlerin yük paylaşımları değişkenlik gösterir. Ayakta dik postürde vücut ağıllığını \%70'inin intervertebral disklere ve \%30'unun ise faset eklemlerine aktarıldığı bildirilmiştir. Alt lomber fasetler, üst seviyedekilere oranla daha çok yük taşırlar (24). Omurgada torsiyonel kuvvetlerin \%55-70'ini intervertebral diskler ile longitudinal ve interspinöz ligamanlar, \%30-45'ini ise bilateral faset eklemleri taşımaktadır $(25,26)$. Lomber faset eklemlerinin anatomik oryantasyonu, bu eklemlerin esas fonksiyonunun torsiyonel kuvvetlerin kontrolü ve stabilizasyonu olduğunu göstermektedir (8). Posterior vertebral yapılar diski aksiyal rotasyonlarda oluşan yirtılmaya yol açabilecek aşır yüklenmelerden korurlar (20). Rotasyonel zorlanmalar en çok $L 4$ ve $L 5$ faset eklemlerini etkilerler. Öne makaslama kuvvetlerinin $1 / 3^{\prime}$ nün faset eklemleri tarafından karşılandığı tahmin edilmektedir (24).

Vertebral kolon ve intervertebral diskin kuvvet dağlımında faset eklemlerinin büyük rolü vardır (20). Lomber spondilozda disk dejenerasyonu durumunda faset eklemleri aksiyal yükün \%70 kadarııı taşıyabilirler. Disk dejenerasyonu yoksa kompresif yükler arttığı için faset ekleminin taşılığı kompresif yük oranı azalır. Lomber aksiyal rotasyon intervertebral disklerin bükülmesini ve faset eklemlerinin sıkışmasına neden olur. Sol aksiyal rotasyonla, sağ alt eklem çıkıntısı sağ üst eklem çıkıntıınna çarpar. Dar faset eklem aralığı, oluşabilen aksiyal hareket genişliğini kısıtlar. Bu durum, intervertebral diskleri aşırı bükücü güçlerden korur, fakat zaman içinde ya da özellikle lomber ekstansiyonla birlikte olduğunda akut olarak faset eklem yaralanmasına yol açabilir. 


\section{Etyopatogenez}

Faset eklem dejenerasyonunda mikrotravmalar, makrotravmalar, fleksiyon ve rotasyonel streslerin oluşturduğu postural nedenler rol oynamaktadır. Rotasyonel zorlanmalar en çok L4 ve L5 faset eklemlerini etkilemektedir. Mikrotravmaların ortaya çıkışında faset asimetrisi gibi yapısal anomaliler önemli rol oynayabilir. Faset asimetrisinde intervertebral diskte mekanik yük dengesiz dağılabilir ve dejenerasyon daha kolay meydana gelebilir $(20,27,28)$.

Yaşın ilerlemesi ile faset eklem dejenerasyonu ve osteoartriti belirgin olarak artar. Başlangıçta sinovyal hücre proliferasyonuna bağlı sinovyal hipertrofi oluşur. Eklem kıkırdağında vertikal fibrilasyon ve subkondral kemik sklerozu, ligamentum flavum ve eklem kapsülünün yapışma yerlerinde osteofitler gelişerek olay ilerler (25). Artiküler fasetlerin dejeneratif değişiklikleri lokal bir inflamasyona neden olarak ağrının sebebi olmaktadır. Asemptomatik gönüllülerde yürütülen bilgisayarlı tomografi (BT) ve manyetik rezonanas görüntüleme (MRG) çalışmalarında faset dejenerasyonu \%8-14 arasında gösterilmiştir (29-31).

Disk dejenerasyonunda disk mesafesi daralır, faset eklemlere binen yük artar ve klinik belirtiler ortaya çıkar. Disk dejenerasyonuyla anüler taşma, fitıklaşma ve erken osteofit formasyonu oluşur. Osteofitler hareket segmentini stabilize etmeye çalışır ancak spinal stenoza da sebep olurlar. Lomber faset eklemler sagittal yerleştiği için, disk dejenerasyonunun faset eklem dejenerasyonundan hızı olması durumunda üst vertebrada retrolistezis olur. Tam tersi durumda ise anterior listezis görülür (32). Kronik disk hastaları ve spondilolistezis sonucu oluşan aks bozukluklarında faset eklemlerin uyumu bozulur. Faset eklemler arasındaki kollaps, dejenerasyon ve eklemi innerve eden sinirlerde irritasyon oluşmaktadır. LFS için tetikleyici faktörler arasında gergin tensor fasia lata, yetersiz gluteus maksimus, lumbalizasyon ve torasik kifozun artması sonucu oluşan kompansatuvar lomber lordoz sayılabilir (33).

\section{Klinik}

Faset eklem ağrısı bel ağrısı sebepleri arasında ön sırada gelmesine rağmen, lokalizasyon çeşitliliği, diğer bel ağrısı sebepleri ile karışabilmesi, izole olmaması nedeni ile tanı koyulması güçtür. Fizik muayene ile faset eklem kaynaklı ağrıyı diğer ağrı sebeplerinden ayıracak net bir manevra yoktur. Bel ağrısı yapabilen hastalıklar arasında semptomlar ve fizik muayene bulgularında birbirine geçiş söz konusudur. Tanı için tam olarak kabul edilmiş bir altın standardın olmaması tanı koymayı güçleştirir.

LFS akut, subakut veya kronik olabilir, genellikle sinsi başlangıçıdır. Bel ağrısı genellikle tek taraflı olup skrotuma, büyük trokantere ve uyluğun arkasına yayılabilir. Radiküler yayılımı olmayan bel ağrısı ve diz altında ağrı görülmemesi faset eklem ağrısı için karakteristiktir. Çok nadir olarak L4-L5 ve L5-S1 faset eklemlerinin ağrısı bacak lateraline ve hatta ayağa bile yayılabilmektedir. Ancak bu hastalarda genellikle bel ağrısı bacak ağrısından daha şiddetlidir. Ağrı ayakta durmakla, lomber ekstansiyon ve olayın olduğu tarafa lateral fleksiyon ve rotasyon ile artar. Faset eklem patolojilerinde özellikle rotasyon hareketleri ağrııdır. Oturmakla ve lomber fleksiyonla azalır. Ayrıca ileri yaş, önceki bel ağrısı öyküsü, normal yürüme, motor ve duyusal defisit olmaması da faset eklem kaynaklı ağrı lehinedir (34). LFS'de lomber lordozun azalması, palpasyonda faset eklemlerinde hassasiyet, düz bacak kaldırma testinin negatif olması, nörolojik defisitin olmaması, intradiskal basıncı artıran manevraların negatifliği olarak sayılabilir. Düz bacak kaldırma testinde 70 derecenin üstünde başlayan ağrı faset eklemi, ligament veya kaslardan kaynaklanabileceğini düşündürmelidir.

Instabilite safhasında bel ağrısı, bel hareketleri sırasında kilitlenme ve belde zayıflık hissedilir. Bu fazda hastanın yakınması daha sık ve ciddidir. Lomber fleksiyon sonrası ekstansiyonda zorlanması ve elleri ile dizlerinden destek alması tipiktir. Radyografik incelemede dinamik anteroposterior grafilerde, sağ ve sol yana eğilme sırasında bir vertebra korpusunun diğeri üzerinde yer değiştirdiği gözlenebilir. Oblik grafide bu durum faset eklem aralığının açılmış veya kötü yerleşimi şeklinde görülebilir. Bilgisayarlı tomografide ise hareketler esnasında faset eklemlerinin açılması ve kapanması görülebilmektedir. Radyografik olarak bu safhada bir veya birkaç seviyede dejeneratif spondilolistezis, genişlemiş ve düzensiz faset eklemleri görülür.

Stabilite safhasında kronik bir bel ağrısı yerleşir. Bel ağrısı künt karakterde, ataklar şeklinde ve sıklıkla miyalji tarzındadır. Kalçaya, gluteal bölgeye, uyluk ve dize yaylımı söz konusudur. Faset eklemlerinin derin palpasyonu ile ağrı mevcuttur. Bu safhada belde yaygın bir hassasiyet, antefleksiyon dışında tüm bel hareketlerinde kısıtllık söz konusudur (35). Ağrı rotasyon hareketi ile artar. Bu fazda artmış bir tutukluluk söz konusudur. Bununla beraber faset eklem kaynaklı ağı dejeneratif disk hastalı̆ı gibi ağırlık dağıımını değiştiren durumlarda daha sık görüldüğünden farklı karakterde ağrılara eşlik edebilir.

Kronik disk hastaları ve spondilolistezis sonucu oluşan aks bozukluklarında artiküler fasetlerin üzerindeki cilt bölgesi palpasyonla ağrıııır. Bu bölge genellikle spinal çıkıntının eklem seviyesindeki 2-3

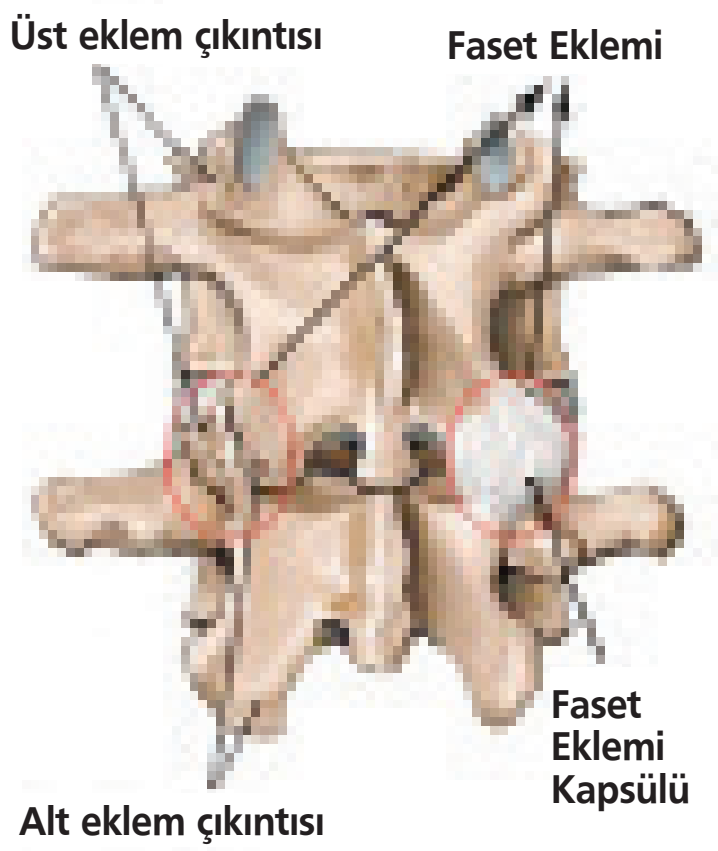

Şekil 1. Faset eklemlerinin anatomisi. 
cm. lateralindeki bölgedir. Bu tür vakalarda faset eklemlerinin lokal anestezik ile infiltrasyonu ağrıyı geçirir. Lokal anestezik ile test pozitif ise genellikle ağrı faset eklemdeki düzensizlikten kaynaklanmaktadır. Bu tür vakaların denervasyondan yarar görebilme şansı çok fazladır. Lokal anestezik infiltrasyonu ağrıya katkı sağlamıyor ise faset denervasyonu gerekli değildir.

Hipertrofik fasetlerin lateral resesleri daraltarak sinir kökünü (root) sıkışırması ile lateral reses sendromu (LRS) ortaya çıkar. LRS'de sinir germe testi karakteristik olarak negatiftir, klinik bulgular ayağa kalkmak ve yürümekle artarken, çömelmek ve oturmakla azalır. LFS gibi ekstansiyonla artan diğer bel ağrısı sebepleri olan pars interarticularis, pedikül ve sakrum yaralanmaları ile sakroiliak eklem ağrısı benzer tablo yaratabilir.

\section{Tanı}

Radyolojik olarak anormal faset eklemi değişikliği prevelansı, yaş ve semptomların varlığına, kullanılan görüntüleme tekniğine göre değişiklik gösterebilmektedir. Tanıda öncelikle lomber omurganın üç yönlü anteroposterior, lateral ve oblik grafilari kullanılıdır. Radyolojik olarak çekilen oblik grafilerde dejeneratif değişiklikler Fujiwara'nın radyolojik değerlendirme sistemi kullanılarak değerlendirilebilir (Tablo1). Hadley'in ' $\mathrm{S}$ ' çizgisi AP ve oblik grafilerde üstteki vertebranın transvers prosesinin alt kısmından başlayan bir çizginin alttaki transvers prosesin üst kısmında devam ettirilmesiyle görülen hafif kıvrımlı bir 'S' harfidir. Faset subluksasyonunda bu çizgi kırılır (36). Lateral grafide spondilolistezis ve instabilite bulgusu için ayakta fleksiyon ve ekstansiyonda çekilen radyografiler oldukça önemlidir. Görüntüleme yöntemleri ile faset eklem dejenerasyonu tesbit edilse dahi hem faset dejenerasyonunun tek başına görülmemesi, hem de ağrının etkilenen eklemlerden farklı seviyelerde görülebilmesi

\section{Tablo 1. Fujiwara'nın radyolojik değerlendirme sistemi}

\begin{tabular}{|c|l|}
\hline Grade 1 & Normal eklem \\
\hline Grade 2 & $\begin{array}{l}\text { Eklem aralı̆ı daralmıs veya hafif osteofit } \\
\text { formasyonu }\end{array}$ \\
\hline Grade 3 & $\begin{array}{l}\text { Skleroz veya orta derece osteofit } \\
\text { formasyonu }\end{array}$ \\
\hline Grade 4 & Ağır osteofit formasyonu \\
\hline
\end{tabular}

Tablo 2. Faset eklem dejenarasyonunun MRG yöntemi ile derecelendirilmesi

\begin{tabular}{|c|l|}
\hline Evre 0 & Normal faset eklemleri \\
\hline Evre 1 & $\begin{array}{l}\text { Eklem aralı̆ında daralma ve/veya ılımlı osteofit } \\
\text { oluşumu ve/veya artiküler prosesin ıımlı } \\
\text { hipertrofisi }\end{array}$ \\
\hline Evre 2 & $\begin{array}{l}\text { Orta derecede osteofit oluşumu veya sklerozla } \\
\text { billikte eklem aralığında daralma ve/veya } \\
\text { artiküler prosesin orta derecede hipertrofisi ve/ } \\
\text { veya ılımlı subartiküler erezyonlar }\end{array}$ \\
\hline Evre 3 & $\begin{array}{l}\text { Belirgin osteofit oluşumu ile birlikte eklemin } \\
\text { daralması ve/veya artiküler prosesin şiddetli } \\
\text { hipertrofisi ve/veya şiddetli subartiküler kemik } \\
\text { erezyonları ve/veya subkondral kistler }\end{array}$ \\
\hline
\end{tabular}

nedeni ile yararı kısıtlıdır. AP ve lateral grafilerde Hadley'in 'S' çizgisi yardımı ile faset subluksasyonu değerlendirilebilirken oblik grafilerde osteoartritin derecesi Fujiwara sınıflandırması ile derecelendirilir. Spesifik olarak faset eklemleri düşünüldüğünde MRG faset effüzyonunu, fasetkistlerinivefasetartrozunugörüntüleyebilmektedir. Faset eklem dejenarasyonu MRG yöntemi ile derecelendirilir (Tablo2). Ancak faset eklem artrozunu tanımlamada BT daha üstündür. Literatürdeki çalışmalarda BT ile dejeneratif faset sendromu insidansı \%40-85 olarak bildirilmiştir $(37,38)$. LFS tanısında intraartiküler faset eklem enjeksiyonları daha spesifiktir. Lomber faset eklem artropatisi tanısında en çok kabul edilen yöntem medial dalın veya faset eklemin intraartiküler blokajıdır $(39,40)$. Blokajdan sonra hastanın ağrısında $\% 50$ ve üzerindeki azalma da test pozitif olarak kabul edilmektedir. Fakat tanısal faset bloklarının yanlış pozitif ve yanlış negatif sonuçlar verebileceği de göz önünde tutulmalıdır (25). Dolayısıyla faset eklem ağrısı tanısı koymada altın standardın ne olduğu hakkındaki tartışma halen devam etmektedir. Faset ağrı tanısı için nükleer tıp yöntemlerinin kullanımına ilgi son yıllarda artmıştır. Basit pozitron emisyon bilgisayarlı tomografi (SPECT) ile gerçekleştirilen kemik taramaları standart kemik taramaları ile kıyaslandığında anatomik lokalizasyon açısından avantaj sağlamıştır (41). Faset sendromunda genellikle normal elektromyografik bulgular görülür (42). Faset sendromlu hastalarda sintigrafi normal sonuç verir. Rutin değerlendirmede kullanılmaz ancak tümör, enfeksiyon ya da fraktürden şüphelenildiğinde yararlıdır.

\section{Tedavi}

Faset eklem sendromu tedavisi medikal tedavi, fizik tedavi, perkütan invazif girişimler ve cerrahi tedavi olarak sınıflandırılabilir. Akut safhada analjezik, miyorelaksan, nonsteroid antiinflamatuar ve antidepresan ilaçlar ile birkaç gün yatak istirahati uygundur $(43,44)$. Bu ilaçlara cevap alınamayan ağrılarda opioidler kullanılabilir. Akut ağrılı dönemlerinde lumbosakral korseleme faydalıdır. Ayrıca uygun zamanda yapılan manipülasyon ve faset eklem enjeksiyonları hastayı hızla rahatlatabilir (45). Günlük yaşamda uygun bel postürünün öğretilmesi ve aerobik egzersizler önerilir. Ayrıca lomber fleksiyon egzersizlerini tercih etmek ve bu amaçla pelvik tilt ve oblik karın kasları ve gluteal bölge kaslarının güçlendirilmesi önemlidir Maniplasyon, mobilizasyon ve germe egzersizleri alt ekstremitede mobiliteyi artııı, kas spazmını çözer, diskin ve faset eklemlerin beslenmesini kolaylaştıır $(46,47)$. Eğer konservatif tedaviye cevap yoksa floroskopi eşliğinde intraartiküler faset eklem enjeksiyonu düşünülmelidir. Intraartiküler steroid enjeksiyonu ile uzun dönem bel ağrısının azalma oranı \%18-63 arasında bildirilmektedir. Diğer tedavi yöntemlerinin başarılı olmadığı durumlarda radyofrekans termokoagülasyonla (RFT) faset denervasyonu uygulanır. RFT, faset eklem denervasyonu için kullanılan en modern yöntem olup sinire kontrollü ısı uygulaması esasına dayanır. Bu teknik bugün için pratik olarak kullanımaktadır. Faset denervasyonu faset eklemlerindeki anormal irritasyona bağı olan spazmı ve dominant şikayet olan ağrıyı ortadan kaldırmaktadır $(48,49)$. Günümüzde BT eşliğinde yapılan RFT tekniği ile denervasyon, daha az invazif olması nedeniyle önerilmektedir. Tüm bu girişimsel tedavi yöntemleri tek bir seans 
olarak uygulanmakta ve hastalar 3-4 saat ya da en fazla 1 gün gözlem altında tutulup taburcu edilebilmektedir. Bu tedavilere yanıtsız hastalara füzyon ameliyatları sıklıkla uygulanmaktadır. Faset cerrahisi uygulanan çalışmaların sonuçları çelişkilidir (50). Cerrahi tedavi sonuçları ile ilgili yeterli kanıt yoktur ve diğer tedavilerden yanıt alınamayan hastalarda uygulanabilmektedir. Hem konservatif hem de cerrahi tedavinin sonuçlarını bildiren çalışmalar, hasta seçiminde ortak kriterler olmaması, uygulanan farklı tedavi yöntemleri, sonuçları değerlendirmede kullanılan kriterlerde farklılıklar ve takip yetersizliği nedeni ile güvenilir olmaktan uzaktır.

\section{Kaynaklar}

1. Goldwaith JE. The lumbosacral articulation: an explanation of many cases of "lumbago," "sciatica" and "paraplegia." Boston Med Surg J 1911;164:365-72.

2. Putti $V$. New conceptions in the pathogenesis of sciatic pain Lancet 1927:2:53-60.

3. Ghormley RK. Low back pain with special reference to the articular facets, with presentation of an operative procedure. JAMA 1933:101:1773-7.

4. Hirsch $C$, Ingelmark BE, Miller M. The anatomical basis for low back pain: studies on the presence of sensory nerve endings in ligamentous, capsular and intervertebral disc structures in the human lumbar spine. Acta Orthop Scand 1963;33:1-17.

5. Mooney V, Robertson J. The facet syndrome. Clin Orthop Relat Res 1976;115:149-56.

6. Douglas E, Kennemore. Percutaneus radiofrequency denervation of spinal facets. Neurosurgery 1985;3:2427-9.

7. Skyreme R. Disconnective neurosurgery. Multiple bilateral percutaneous rhizolysis (Faset Rhizotomy). Current conroversies in neurosurgery. Philadelphia : WB Saunders Company; 1976;80-8

8. Schwarzer AC, Aprill CN, Derby R, Fortin J, Kine G, Bogduk N. The relative contributions of the disc and zygapophyseal joint in chronic low back pain. Spine 1994;19:801-6.

9. Schwarzer AC, Derby R, Aprill CN, Fortin J, Kine G, Bogduk N. The value of the provocation response in lumbar zygapophyseal joint injections. Clin J Pain 1994;10:309-13.

10. Glover JR. Arthrography of the joints of the lumbar vertebral arches. Orthop Clin North Am 1977;8:37-42

11. Bogduk N. Clinical anatomy of the lumbar spine and sacrum, 3rd edition. Edinburgh: Churchill Livingstone; 1997.

12. Ashton IK, Ashton BA, Gibson SJ, Polak JM, Jaffray DC, Eisenstein SM. Morphological basis for back pain: The demonstration of nerve fibers and neuropeptides in the lumbar facet joint capsule but not in ligamentum flavum. J Orthop Res 1992;10:72-8.

13. el-Bohy A, Cavanaugh JM, Getchell ML, Bulas T, Getchell TV, King Al. Localization of substance $P$ and neurofilament immunoreactive fibers in the lumbar facet joint capsule and supraspinous ligament of the rabbit. Brain Res 1988;460:379-82.

14. Willburger RE, Wittenberg $\mathrm{RH}$. Prostaglandin release from lumbar disc and facet joint tissue. Spine 1994;19:2068-70.

15. Igarashi A, Kikuchi S, Konno S, Olmarker K. Inflammatory cytokines released from the facet joint tissue in degenerative lumbar spinal disorders. Spine 2004;29:2091-5.

16. Tuzun S. Bel ve bacak ağrıları. In: Tuzun F (ed). Hareket sistemi hastalıkları, Istanbul, Nobel Kitabevi, 1997

17. Tuzun S. Lomber disk hernisinde risk faktörleri ve prognoz. In: Tuzun F, Toros H (eds). Bel ağrıları ve lomber disk sendromları, Istanbul, Nobel Kitabevi, 2004

18. Falco EJF, Onjewu CO, Irwin LF, Daniel W, Zhu K. Periferik eklem, yumuşak doku ve omurga enjeksiyon teknikleri. In: Braddom RL (ed). Fiziksel Tıp ve Rehabilitasyon, 3rd ed. Ankara, Güneş Tıp Kitabevi, 2010.

19. Kaplan M, Dreyfuss P, Halbrook B, Bogduk N. The ability of lumbar medial branch blocks to anesthetize the zygapophysial joint. Spine 1998;23:1847-52.

20. International Spine Intervention Society. Practice Guidelines for Spinal Diagnostic\&Treatment Procedures. San Francisco, 2004

21. Fehlandt AF Jr, Micheli LJ. Lumbar facet stress fracture in a ballet dancer. Spine 1993;18:2537-9.

22. Schendel MJ, Wood KB, Buttermann GR, Lewis JL, Ogilvie $\mathrm{JW}$. Experimental measurement of ligament force, facet force, and segment motion in the human lumbar spine. J Biomech $1993: 26: 427-38$
23. Schendel MJ, Wood KB, Buttermann GR, Lewis JL, Ogilvie JW. Orientation of the lumbar facet joints: association with degenerative disc disease. J Bone Joint Surg Am 1996;78:403-11.

24. Grobler LJ, Robertson PA, Novotny JE, Pope MH. Etiology of spondylolisthesis: assessment of the role played by lumbar facet joint morphology. Spine 1993;18:80-91.

25. O'Neill C, Owens DK. Lumbar facet joint pain: time to hit the reset button. Spine 2009:9:619-22.

26. Pneumaticos SG, Chatziioannou SN, Hipp JA, Moore WH, Esses SI. Low back pain: prediction of short-term outcome of facet joint injection with bone scintigraphy. Radiology 2006;238:693-8.

27. Adams MA, Hutton WC. The mechanical function of the lumbar apophyseal joints. Spine 1983;8:327-30

28. Vad VB, Cano WG, Basrai D, Lutz GE, Bhat AL. Role of radiofrequency denervation in lumbar zygapophyseal joint synovitis in baseball pitchers: a clinical experience. Pain Phys 2003:6:307-12

29. Weishaupt D, Zanetti M, Hodler J, Boos N. MR imaging of the lumbar spine: Prevalence of intervertebral disk extrusion and sequestration, nerve root compression, end plate abnormalities, and osteoarthritis of the facet joints in asymptomatic volunteers. Radiology 1998;209:661-6

30. Wiesel SW, Tsourmas N, Feffer HL, Citrin CM, Patronas N. A study of computer-assisted tomography: I. The incidence of positive CAT scans in an asymptomatic group of patients. Spine 1984:9:549-51.

31. Jensen MC, Brant-Zawadzki MN, Obuchowski N, Modic MT, Malkasian D, Ross JS. Magnetic resonance imaging of the lumbar spine in people without back pain. N Engl J Med 1994;331:69-73.

32. Cavanaugh JM, Ozaktay AC, Yamashita HT, King Al. Lumbar facet pain: biomechanics, neuroanatomy, and neurophysiology. J Biomech 1996:29:1117-29.

33. Hourigan CL, Bassett JM. Facet syndrome: clinical signs, symptoms, diagnosis, and treatment. J Manipulative Physiol Ther 1989:12:293-7.

34. Jackson RP, Jacobs RR, Montesano PX. Facet joint injection in lowback pain: A prospective statistical study. Spine 1988;13:966-71.

33. Morris JM, Lucas DB, Bresler B. Role of the trunk in stability of the spine. J Bone Joint Surg 1961;43:327-51.

36. Murtagh FR. Computed tomography and fluoroscopy guided anesthesia and steroid injection in facet syndrome. Spine 1988:13:686-9

37. Carrera GF. Lumbar facet joint injection in low back pain and sciatica: Preliminary results. Radiology 1980;137:665-7.

38. Carrera GF, Williams AL. Current concepts in evaluation of the lumbar facet joints. Crit Rev Diagn Imaging 1984;21:85-104

39. Dreyer SJ, Dreyfuss PH. Low back pain and the zygapophysial (facet) joints. Arch Phys Med Rehabil 1996;77:290-300.

40. Dreyfuss PH, Dreyer SJ. Lumbar zygapophysial (facet) joint injections. Spine J 2003;350-9.

41. Willick SE, Kendall RW, Roberts ST. An emerging imaging technology to assist in the localization of axial spine pain. PMR 2009:1:89-92.

42. Gries NC, Berlemann U, Moore RJ, Vernon-Roberts B. Early histologic changes in lower lumbar discs and facet joints and their correlation. Eur Spine J 2000:9:23-9.

43. Roelofs PD, Deyo RA, Koes BW, Scholten RJ, van Tulder MW. Nonsteroidal anti-inflammatory drugs for low back pain: an updated Cochrane review. Spine 2008;33:1766-74.

44. Van Tulder Mw, Touray T, Furlan AD, Solway S, Bouter LM. Muscle relaxants for nonspecific low back pain: a systematic review within the framework of the cochrane collaboration. Spine 2003:28:1978-92.

45. Heymans MW, van Tulder MW, Esmail R, Bombardier C, Koes BW. Back schools for nonspecific low back pain: a systematic review within the framework of the Cochrane Collaboration Back Review Group. Spine 2005;30:2153-63.

46. Flynn WT, Fritz J, Wainner R, Whitman J. Philedelphia Pane evidence-based clinical practice guidelines on selected rehabilitation interventions for lowback pain. Phys Ther 2001;81:1641-74.

47. Busanich BM, Verscheure SD. Does Mckeinze therapy improve outcomes for back pain? J Athl Train 2006:41:117-9.

48. Sluijter ME. Radiofrequency, Part 1: The lumbosacral region. Switzerland, FlivoPress, 2001.

49. Mullan S, Hekmatpanah J, Dobbin G. Percutaneus intramedullary cordotomi utilizing the unipolar anodal electrolytic lesion. J Neurosurgery 1965:22:548-53

50. Manchikanti L, Pampati V, Fellows B, Baha AG. The inability of the clinical picture to characterize pain from facet joints. Pain Physician 2000;3:158-66. 